DOI: 10.20472/IAC.2018.044.051

\author{
BOB UTTL \\ Mount Royal University, Canada \\ AMY SIEGENTHALER \\ Foothills Medical Center, Canada \\ ANNE TSEU \\ Mount Royal University, Canada
}

\title{
THE END OF FLYNN EFFECT: A META-ANALYSIS OF THE WAIS-R VOCABULARY SCORES
}

\begin{abstract}
:
The Flynn Effect refers to substantial increases in intelligence scores over most of the 20th century. However, a number of recent findings suggest that the Flynn Effect may have plateaued or even reversed. We examined whether scores on Wechsler Adult Intelligence Scale - Revised (WAIS-R) Vocabulary Subset are still increasing, levelled off, or declining in Canada and United States. Following the methodology described in Uttl and Van Alstine (2003), we searched full text of Aging and Psychology, Journals of Gerontology: Series B, and Experimental Aging Research for samples of normal healthy adults who were administered WAIS-R Vocabulary Subtest as part of variety of different studies. To determine whether the WAIS-R Vocabulary scores have been increasing, plateauing, or declining, we used year of publication as a proxy for the year of assessment and used meta-regression analyses to determine changes in WAIS-R Vocabulary scores, if any. Our results show no further increases in WAIS-R Vocabulary scores and suggest that the Flynn Effect has ended for vocabulary tests in North America.
\end{abstract}

\section{Keywords:}

Flynn Effect, WAIS-R, Vocabulary scores 